\title{
Avaliação de compostos bioativos em pessegada
}

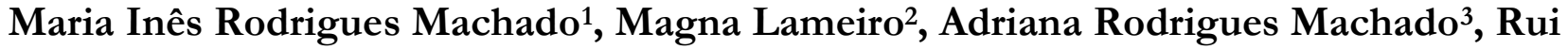 \\ Carlos Zambiazi ${ }^{4}$ e José Valmir Feitosa ${ }^{5}$
}

O objetivo deste trabalho foi selecionar algumas cultivares de pêssego para produção de polpa e, após um período de armazenamento, elaborar massa de pêssego doce, avaliando as características físicas, químicas, microbiológicas e o teor de compostos bioativos. Além disso, pretendeu-se avaliar a estabilidade de compostos bioativos na polpa de pêssego e na massa de pêssego doce armazenada por um período de 10 meses. Para isso, foram selecionadas três cultivares de pessegueiro Maciel, Santa Áurea e Esmeralda, que foram processadas separadamente para as cultivares, e também, foi selecionado um lote com uma mistura de cultivares. As determinações físico-químicas e bioativas dos compostos foram realizadas, incluindo sólidos solúveis, testando o teor de pectina nas polpas, acidez total, $\mathrm{pH}$, compostos fenólicos totais, compostos fenólicos individuais, determinação microbiológica de leveduras e bolores e análise sensorial. Os resultados das análises físico-químicas de frutas frescas mostraram frutos de excelente qualidade. No entanto, houve redução significativa no teor de compostos fenólicos e na ausência de carotenóides. Verificou-se que, mesmo com um menor teor de sólidos solúveis em uma das amostras, foi atingido o ponto de corte, demonstrando que é possível atingir o ponto final da massa doce de pêssego em um período menor de cozimento.

Palavras-chave:Pêssego da polpa. Armazenamento. Massa de pêssego doce.

\section{Evaluation of bioactive compounds in pessegada}

The aim of this study was to select some peach cultivars for pulp production and, after a storage period to prepare sweet peach mass evaluating the physical, chemical, microbiological and bioactive compounds content. Furthermore, it was intended to evaluate the stability of bioactive compounds in the peach pulp and in the mass of sweet peach stored for a period of 10 months. In this regard three peach cultivars (Maciel, Santa Áurea and Esmeralda) were selected, which were processed separately for the //cultivars and also a batch was selected with a mixture of cultivars. The physico-chemical and bioactive determinations of the compounds were carried out including soluble solids by testing the pectin content in the pulps, total acidity, $\mathrm{pH}$, total phenolic compounds, individual phenolic compounds, microbiology-ical determination of yeasts and molds and sensory analysis. The results of the physical-chemical analyzes of fresh fruits showed fruits of excellent quality. However, there was a

\footnotetext{
${ }^{1}$ Programa de Pós-graduação em Ciência e Tecnologia de Alimentos. Campus Universitário - Universidade Federal de Pelota. Endereço para Correspondência: Rua Ícaro de Sousa Moreira, s/n - Bairro Barro Branco, Crato - Ceará. CEP: 63.130-025. Tel: +55 (88) 3521-7364. E-mail: ines.machado@ufca.edu.br

2 Programa de Pós-graduação em Ciência e Tecnologia de Alimentos. Campus Universitário-Universidade Federal de Pelota

3 Programa de pós-graduação Engenharia Ciência e Tecnologia de Alimentos /FURG;

${ }^{4}$ Centro de Ciências Químicas, Farmacêuticas e de Alimentos/UFPel.

${ }^{5}$ Prof. Associado II da Universidade Federal do Ceará do Cariri.
} 
significant reduction in the content of phenolic compounds and in the lack of carotenoids. It was found that even with a lower soluble solids content in one of the samples the cut-off point was reached demonstrating that it is possible to reach the end point of the sweet peach mass in a shorter cooking period.

Keywords:Pulp Peach. storage. Sweet peach mass.

\section{INTRODUÇÃO E OBJETIVOS}

O consumo de frutas e hortaliças sempre foi valorizado pelos benefícios que esses alimentos podem trazer à saúde, devido à grande quantidade de vitaminas, minerais e fibras que possuem neste contexto o pêssego apresenta-se como boa fonte de compostos antioxidantes, tais como vitaminas do complexo A, B, C e E, compostos fenólicos e carotenoides, além de ser uma importante fonte de minerais como cálcio, magnésio e fibras ${ }^{[1,2,3,4]}$. Sabese que as perdas na agricultura são elevadas, tanto do ponto de vista da produção quanto do consumo. Ao evitá-las ou diminuí-las são reduzidos custos, mão de obra e energia. Na maioria das vezes, este desperdício deve-se tanto ao desconhecimento quanto ao aproveitamento racional desta produção[5]. No entanto, quase a totalidade da produção de pêssegos é industrializada na forma de fruto em calda, o que gera uma carência de pesquisa e desenvolvimento de tecnologias para a utilização em outros produtos ${ }^{[6]}$. Normalmente a indústria processadora de pêssegos não realiza controle sobre as cultivares de frutos que recebe, e que processa, especialmente levando em consideração apenas o estádio de maturação dos frutos. Além disto, é uma prática comum nas indústrias processadoras de pêssegos, processar os frutos na forma de polpas e estocá-las, para uma utilização posterior em períodos de entre safras. Entre os métodos de conservação utilizados para manter as características das polpas, por longos períodos, destacam-se a conservação por métodos combinados para polpas e pelo uso do açúcar na elaboração de doces em massa (pessegada), visto[7,8]; que a produção dos frutos que consiste na matéria prima destes produtos é sazonal. Sendo assim, objetivo deste estudo foi escolher algumas cultivares de pêssego para elaborar polpa e após um período de estocagem elaborar a pessegada, avaliando as características físico-químicas, microbiológicas e sensoriais e o conteúdo de compostos bioativos.

\section{MATERIAL E MÉTODOS}

\section{Matéria}

Para o desenvolvimento do presente estudo foram escolhidas três cultivares de pêssegos (Prunus pérsica): Santa Áurea, Esmeralda e Maciel; todas provenientes de cinco produtores ligados a uma empresa conserveira da região. Além de pêssegos destas três cultivares, utilizou-se um lote de pêssegos, denominado de mistura, o qual foi constituído de uma composição de cultivares de pêssegos recebidos na indústria, os quais apenas tiveram acompanhamento na produção, sem prévia classificação por cultivares, o qual também foi utilizado para a elaboração de polpa.

\section{Elaboração da Polpa}

As polpas foram preparadas com o lote de uma mistura de cultivares e, separadamente por cultivares de pêssego selecionadas, seguindo as recomendações da legislação[?]. O processo consistiu em pelagem, corte, despolpamento e cocção da massa, como conservante foi adicionado a polpa sorbato de potássio (1 g. kg-1) e a seguir o envase ocorreu em embalagens aluminizadas, as quais foram acondicionadas em tambores assépticos, devidamente identificados, os quais foram mantidos na temperatura ambiente pelo período de 10 meses. 


\section{Elaboração do Doce em Massa}

Para elaboração do doce em massa, foram utilizadas as polpas armazenadas.

\section{Pessegada}

Para a definição das formulações foi realizada avaliação das características da polpa estocada, obedecendo à relação polpa/sacarose 1:1. No teor de pectina ocorreu uma redução de $50 \%$ do valor da formulação original (mistura) a qual era de $1,5 \%$. Contudo, a mesma condição foi adotada para a adição do ácido cítrico, onde na formulação original (mistura) seu consumo era em torno de $0,3 \%$ sobre o total da formulação, passando para valores decrescentes como proposta para elaboração de pessegada com cultivares selecionadas. Assim, com a utilização de matéria-prima de cultivares selecionadas possibilitou uma redução no percentual dos insumos utilizados, e mesmo assim atingindo o ponto final do doce.

Quanto ao teor estabelecido para pectina foi considerado o poder geleificante da pectina de $0,66 \%$ na condição padrão de $\operatorname{processo}^{[10]}$; no entanto, para o processo industrial foi proposto 0,83\% visando corrigir desvios no processamento. Desta forma, o armazenamento da polpa de pêssego para posterior produção da pessegada propicia uma redução na adição de ácido. Normalmente para a produção de pessegada são adicionados $0,3 \%$ de ácido cítrico; no entanto, com o armazenamento da polpa e os resultados verificados para as amostras individualmente este valor foi reduzido, visando manter acidificação no padrão mínimo de $\mathrm{pH}$ estabelecido para processamento $(\mathrm{pH}: 3,2)$, sendo assim os valores acrescidos foram até $0,12 \%$ para a cultivar Esmeralda, 0,04\% para a cultivar Santa Áurea e $0,02 \%$ para a cultivar Maciel.

Isto representa uma redução importante nos custos de produção da pessegada decisões que são comuns em procedimentos operacionais de produção, mas somente através dos resultados obtidos após o armazenamento é que foi possível realizar a diminuição do percentual de ácido a ser acrescido. O grau de maturação da fruta para elaboração de doce em massa (pessegada) deve ser de produto com maturação adequada para indústria, o que facilita a obtenção do ponto final de corte, pois espera-se que a polpa apresente conteúdo de pectina que propicie a redução da quantidade a ser adicionada na pessegada. $\mathrm{Na}$ tabela 2 estão os dados de caracterização das pessegadas logo após o processamento e após a estocagem pelo período de 10 meses, elaboradas com pêssegos de cultivares selecionadas e com a mistura de cultivares.

\section{Caracterização físico-química e conteúdo de compostos bioativos}

A avaliação físico-química e de compostos bioativos foi determinada nas pessegadas, logo após processadas e após o período de 10 meses de estocagem, através de análises em triplicata de: $\mathrm{pH}$ (Potencial hidrogeniônico). Determinado em potenciômetro Digimed - DM-20, com a amostra à temperatura de $20^{\circ} \mathrm{C}$. Segundo metodologia descrita pelo Instituto Adolfo Lutz ${ }^{[11]}$.

\section{Sólidos solúveis totais (SS)}

Determinado por leitura direta em refratômetro de bancada, marca nalytikjena, sendo os resultados corrigidos para a temperatura de $20^{\circ} \mathrm{C}$, através de tabela de correção, e expressos em ${ }^{\circ}$ Brix.

\section{Acidez total titulável (AT)}

Método volumétrico, através de titulação com $\mathrm{NaOH} 0,1 \mathrm{~N}$, sendo os resultados expressos em \% de ácido cítrico ${ }^{[1]}$. 


\section{Teste do teor de pectina}

A nível industrial a precipitação com álcool fornece resultado suficientemente exato para uma avaliação dessa substância. $O$ teste foi realizado a partir da adição de $1 \mathrm{~mL}$ de polpa à $3 \mathrm{~mL}$ de álcool, seguido de leve agitação e repouso por 5 minutos. Polpa rica em pectina resulta um coágulo firme. Teor médio de pectina ocorre a formação de coágulos pouco firme, fragmentando-se. Caso teor de pectina na amostra resulte pouco expressivo, não ocorre a formação de coágulos ${ }^{[2]}$.

\section{Determinação do conteúdo total de compostos fenólicos}

Realizada de acordo com o método colorimétrico utilizando o reagente FolinCiocalteau ${ }^{[13]}$, com poucas modificações. Pesaram-se 2 gramas de amostra previamente triturada e diluiuse em $20 \mathrm{~mL}$ de metanol. A amostra foi homogeneizada a cada 5 minutos durante 3 horas a temperatura ambiente. Filtrou-se com algodão, transferindo o extrato clarificado para balão volumétrico de $50 \mathrm{~mL}$, completando-se o volume com metanol. Para realizar a quantificação do total dos compostos fenólicos, utilizou-se $1 \mathrm{~mL}$ do extrato clarificado, ao qual foi adicionado $1,5 \mathrm{~mL}$ de solução de carbonato de sódio a $20 \%$ em NaOH 0,1 M. Deixou-se 2 horas em banho maria à $37^{\circ} \mathrm{C}$ e então foi adicionado $0,5 \mathrm{~mL}$ de reagente de FolinCiocalteau diluído $(1: 2, \mathrm{v} / \mathrm{v})$ em água ultra pura. Após realizou-se a leitura em espectrofotômetro (modelo Ultrospec 2000) a $765 \mathrm{~nm}$, usando metanol para leitura do branco. Procedeu se a elaboração da curva padrão de ácido gálico para a quantificação dos compostos fenólicos. Os resultados foram expressos em mg de ácido gálico.100 g-1 amostra fresca. A quantificação foi baseada no estabelecimento de uma curva padrão com 0; 50; 100; 150; 250 e 500 mg.L-1 de ácido gálico, obtendo-se uma equação polinomial expressa por: y $=0,0085 \mathrm{x}+1460,0255 \mathrm{com}$ um coeficiente de determinação de $98,23 \%$.

\section{Determinação do conteúdo de compostos fenólicos Individuais}

Os compostos fenólicos foram extraídos da polpa das frutas usando o método descrito por Häkkinen[14], com poucas modificações. Cinco gramas da amostra macerada foram dissolvidas em $30 \mathrm{~mL}$ de metanol e após foi adicionado $4,9 \mathrm{~mL}$ de ácido clorídrico p.a. (concentração final de $\mathrm{HCl}$ 1,2 $\mathrm{M})$, sendo completado o volume em balão volumétrico de $50 \mathrm{~mL}$ com metanol. O extrato foi homogeneizado em banho de água à $35^{\circ} \mathrm{C}$, na ausência de luz por 24 horas. Após este período, a mistura foi filtrada e o sobrenadante foi concentrado em rotaevaporador a $40^{\circ} \mathrm{C}$ por cerca de 30 minutos.

O resíduo concentrado foi redissolvido em metanol até o volume final de $5 \mathrm{~mL}$, o qual foi centrifugado (7.000 rpm por 10 minutos). Retirouse uma alíquota do sobrenadante $(30 \mu \mathrm{L})$ para injetar no cromatógrafo. $\mathrm{O}$ cromatógrafo consistiu no sistema HPLC-Shimadzu, com injetor automático, detector UV-visível a $280 \mathrm{~nm}$, coluna de fase reversa RP-18 CLC-ODS $(5 \mu \mathrm{m}$, 4,6 $\mathrm{mm} \times 150 \mathrm{~mm}$ ) com fase estacionária octadecil e uma coluna de guarda CLCGODS (4) com fase estacionária de superfície octadecil, ambas localizadas em forno a $25^{\circ} \mathrm{C}$.

A fase móvel consistiu no gradiente de eluição utilizando solução aquosa de ácido acético (99:1, v/v) e metanol, com fluxo de $0,8 \mathrm{~mL} \mathrm{~min}{ }^{-1}$, com um tempo total de corrida de 45 minutos, segundo metodologia descrita por Zambiazi[15]. Os compostos fenólicos individuais foram quantificados com base da curva decalibração dos padrões externos, cujos padrões (grau espectrofotométrico) foram dissolvidos em metanol. A concentração das soluções dos padrões variou de 0,125 a $12,5 \mu$ g. $25 \mu \mathrm{L}-1$ para o ácido p-cumárico, ácido cafeico, quercetina, ácido ferúlico, epicatequina, ácido p-hidroxibenzoico, ácido gálico e ácido elágico, com as respectivas equações expressa por: $\mathrm{y}=2,14083 \mathrm{e}-007 \mathrm{x}$, com $R^{2}$ : 0,990365 (ácido p-cumárico), $y=2,93335 \mathrm{e} 007 \mathrm{x}$, 
com R2:0,998939 (ácido cafeico), y $=6,24982 \mathrm{e}-$ 007x, com $R^{2}: 0,992693$ (quercetina), $y=$ 3,27162e-007x, com $R^{2}: 0,999562$ (ácido ferúlico), $\mathrm{y}=1,35909 \mathrm{e}-006 \mathrm{x}, \quad$ com $\quad R^{2}: \quad 0,997793$ (epicatequina), $\mathrm{y}=6,44575 \mathrm{e}-007 \mathrm{x}$, com $R^{2}$ : 0,995523 (ácido phidroxibenzoico), y = 3,25519e007x, com $R^{2}$ : 0,996997 (ácido gálico), $\mathrm{y}=$ 5,8751e-007x, com R²: 0,997719 (ácido elágico), de 1,25 a $87,5 \mu$ g. $25 \mu \mathrm{L}-1$ para catequina $(\mathrm{y}=$ 5,8751e-007x, com $\left.R^{2}: 0,997719\right)$, e de 0,125 a

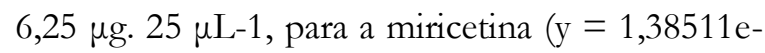
$007 x$, com $\left.R^{2}: 0,995137\right)$ e a mesma concentração para o kaempferol $\left(y=5,6644 \mathrm{e}-007 x\right.$, com $R^{2}$ : 0,999088). Os resultados foram expressos em miligramas por 100 gramas de peso da fruta in natura. Os padrões cromatográficos para a determinação de fenóis individuais foram obtidos da Sigma (St. Louis, MO) e Fluka (Milwaukee, WI), todos com $96-99 \%$ de pureza.

\section{Avaliação estatística}

Com auxílio do software Statistica versão 7.0[16] os dados da análise físico-química, caracterização físico-química e conteúdo de compostos fenólicos individuais de pêssego in natura e da polpa armazenada por 10 meses dos cultivares, Esmeralda, Santa Áurea, Maciel e mistura submetidos à análise de variância (ANOVA) para verificar a normalidade dos erros e homogeneidade de variância e as médias comparadas pelo teste de Tukey ao nível de significância de 5\%.

\section{RESULTADOS E DISCUSSÃO}

\section{Polpa de pêssego}

$\mathrm{Na}$ Tabela 1 estão os resultados da análise físico-química da fruta in natura e da polpa processada, a qual foi envasada em sacos aluminizados que foram acondicionados em tambores assépticos, e estocados pelo período de dez meses à temperatura ambiente.

Para a seleção das cultivares de pêssego que foram utilizadas no processamento (Tabela 1), foi priorizado que as categorias escolhidas acompanhassem a tendência nacional que está focada principalmente no requisito de cultivar de pêssego própria para a indústria. Dentre estas incluem-se as cultivares cujos frutos possuem caroço aderido ou semi-áderido à polpa. As cultivares escolhidas foram: Esmeralda e Santa Áurea, as quais apresentam polpa e epiderme amarela, maior teor de acidez ${ }^{[17]}$ ausência de coloração vermelha junto ao caroço e caroço geralmente aderente e a cultivar Maciel, conhecida como dupla finalidade (semicling), a qual contém caroço sem aderido, por apresentar polpa firme com maior sabor, maior teor de acidez, maior teor de açúcar, epiderme amarela e com uma coloração mais avermelhada, e também com grande potencial para o processamento de polpas ${ }^{[18,19]}$. 
Tabela 1: Determinações físico-químicas de pêssego in natura e da polpa armazenada por 10 meses.

\section{Pêssego in natura}

\begin{tabular}{cccccc}
\hline Cultivar & $\mathrm{pH}$ & $\mathrm{SS}\left({ }^{\circ}\right.$ Brix $)$ & AT $(\%)$ & S/AT & $\begin{array}{c}\text { Compostos fenólicos } \\
\left(\mathrm{mg}^{\circ} 100 \mathrm{~g}^{-1}\right)\end{array}$ \\
\hline Mistura & $3,56 \pm 0,02^{\mathrm{c}}$ & $11,00 \pm 0,12^{\mathrm{d}}$ & $0,68 \pm 0,01^{\mathrm{c}}$ & $14,0^{\mathrm{c}}$ & $\begin{array}{c}11,25 \pm 0,06^{\mathrm{c}} \\
10,24 \pm 0,04^{\mathrm{dC}}\end{array}$ \\
\hline Esmeralda & $3,82 \pm 0,02^{\mathrm{aA}}$ & $12,00 \pm 0,16^{\mathrm{bC}}$ & $0,60 \pm 0,02^{\mathrm{dF}}$ & $20,0^{\mathrm{a}}$ & $11,45 \pm 0,13^{\mathrm{bC}}$ \\
\hline Santa Áurea & $3,52 \pm 0,01^{\mathrm{dC}}$ & $12,90 \pm 0,19^{\mathrm{aA}}$ & $0,83 \pm 0,04^{\mathrm{bE}}$ & $15,5^{\mathrm{b}}$ & $16,20 \pm 0,25^{\mathrm{aA}}$ \\
\hline Maciel & $3,64 \pm 0,04^{\mathrm{bB}}$ & $11,50 \pm 0,08^{\mathrm{cD}}$ & $0,89 \pm 0,02^{\mathrm{aD}}$ & $13,0^{\mathrm{d}}$ & \\
\hline
\end{tabular}

Polpa de pêssego estocada por 10 meses

\begin{tabular}{cccccc}
\hline Cultivar & $\mathrm{pH}$ & $\mathrm{SS}\left({ }^{\circ} \mathrm{Brix}\right)$ & $\mathrm{AT}(\%)$ & $\mathrm{S} / \mathrm{AT}$ & $\begin{array}{c}\text { Compostos fenólicos } \\
\left(\mathrm{mg}^{\circ} 100 \mathrm{~g}^{-1}\right)\end{array}$ \\
\hline Mistura & $3,35 \pm 0,04 \mathrm{~b}$ & $12,00 \pm 0,15^{\mathrm{c}}$ & $1,33 \pm 0,12^{\mathrm{b}}$ & $\mathrm{S} / \mathrm{FG}$ & $11,92 \pm 0,11^{\mathrm{c}}$ \\
Esmeralda & $3,38 \pm 0,02^{\mathrm{bE}}$ & $12,90 \pm 0,25^{\mathrm{aA}}$ & $1,20 \pm 0,03^{\mathrm{dC}}$ & $\mathrm{C} / \mathrm{FG}^{* *}$ & $9,65 \pm 0,01 \mathrm{dD}$ \\
\hline Santa Áurea & $3,20 \pm 0,06^{\mathrm{cF}}$ & $11,00 \pm 0,16^{\mathrm{dE}}$ & $1,50 \pm 0,08^{\mathrm{aA}}$ & $\mathrm{C} / \mathrm{FG}$ & $12,49 \pm 0,56^{\mathrm{bB}}$ \\
\hline Maciel & $3,47 \pm 0,01^{\mathrm{aD}}$ & $12,70 \pm 0,05^{\mathrm{bB}}$ & $1,30 \pm 0,02^{\mathrm{cB}}$ & $\mathrm{S} / \mathrm{FG}^{* * *}$ & $15,68 \pm 0,26^{\mathrm{aA}}$
\end{tabular}

Letras distintas minúsculas na mesma coluna entre mistura e cultivares para pêssego in natura indicam diferença significativa pelo teste de Tukey, em nível de 5\% de probabilidade. Letras distintas minúsculas na mesma coluna entre mistura e cultivares para polpa de pêssego estocada por 10 meses indicam diferença significativa pelo teste de Tukey, em nível de $5 \%$ de probabilidade. Letras maiúsculas distintas na mesma coluna entre cultivares para pêssego in natura e polpa de pêssego estocada por 10 meses indicam diferença significativa pelo teste de Tukey, em nível de $5 \%$ de probabilidade.

*Valores médios obtido de três repetições \pm desvio padrão.

**C/FG-com formação de grumos. ***S/FG-sem formação de grumos

Fonte: Dados obtidos. Crato-CE. Julho (2017).

Quanto ao período de colheita, todas as cultivares apresentam ponto de colheita no mês de dezembro. O volume de oferta de frutas foi uma consideração importante para evitar possíveis quebras de safra e volume menor do que o esperado a ser entregue na empresa. A cultivar de pêssego Esmeralda apresentou-se com valor de $\mathrm{pH}$ superior e conteúdo de acidez inferior que as demais, demonstrando ser um fruto menos ácido. A cultivar Santa Áurea apresentou o menor valor de $\mathrm{pH}$, no entanto, o teor de acidez não diferiu da cultivar Maciel.
De acordo com a análise da relação de sólidos solúveis/acidez titulável das três cultivares estudadas, observou-se diferenças estatísticas significativas, destacando-se a cultivar Esmeralda, com teor de SS/AT de 20, onde seu teor de sólidos solúveis foi de $12^{\circ}$ brix, demonstrando ser um fruto de maior equilíbrio entre o teor de açúcares e acidez $^{[18]}$. Segundo Fachinello \& Nachtigal[19], embora outros compostos também estejam envolvidos, o teor de sólidos solúveis totais fornece um indicativo da quantidade de açúcares presente nas frutas. 
A (AT) normalmente diminui com o avanço do estágio de maturação, sendo que o valor de $\mathrm{pH}$ apresenta comportamento inverso, ou seja, aumenta com o estádio de maturação da fruta. Chitarra ${ }^{[20]}$ considera a relação Sólidos Solúveis/Acidez Total (SS/AT) uma das melhores formas de avaliação do sabor de um fruto[21], por ser um indicativo da possível interação doçura/acidez. Silva também destaca que o teor de sólidos solúveis dos frutos é de grande importância, tanto para o consumo in natura como para o processamento industrial, pois altos teores de sólidos solúveis na matéria-prima implicam na adição de menores quantidades de açúcares, menor tempo de evaporação da água durante $\mathrm{O}$ processamento de polpas, menor gasto de energia e maior rendimento do produto, resultando em maior economia no processamento.

Tanto a polpa padrão (Tabela 1) quanto as elaboradas com cultivares selecionadas armazenadas por 10 meses, apresentaram redução no valor de $\mathrm{pH}$ e consequente aumento no teor de acidez titulável, em relação ao fruto in natura. Isto indica que seja possível que tenha ocorrido processo fermentativo em pequena escala, provavelmente por leveduras naturalmente presentes no pêssego que resistiram ao processo de cozimento. O processo fermentativo pode justificar o aumento da acidez da polpa armazenada decorrente da produção microbiana de ácidos orgânicos no processo anaeróbio. No entanto, a pequena alteração de $\mathrm{pH}$ da polpa armazenada também pode estar relacionada ao efeito tamponante do sorbato de potássio, adicionado para auxiliar na conservação do produto.

Mesmo que tenha ocorrido um lento processo fermentativo, não inferiu na hidrólise substancial de polissacarídeos como pectina, principalmente das cultivares Esmeralda e Santa Áurea, que apresentaram formação de grumos na prova do álcool, o que auxiliou na redução do uso de pectina comercial para a produção de pessegada. A catequina, epicatequina, quercetina, ácido gálico e o ácido hidróxibenzóico, foram os compostos fenólicos identificados por cromatografia líquida de alta eficiência nas polpas estocadas pelo período de 10 meses (Tabela 2).

Tabela 2: Caracterização físico-química das pessegadas elaboradas com cultivares selecionadas e com a mistura de cultivares.

\section{Pessegada}

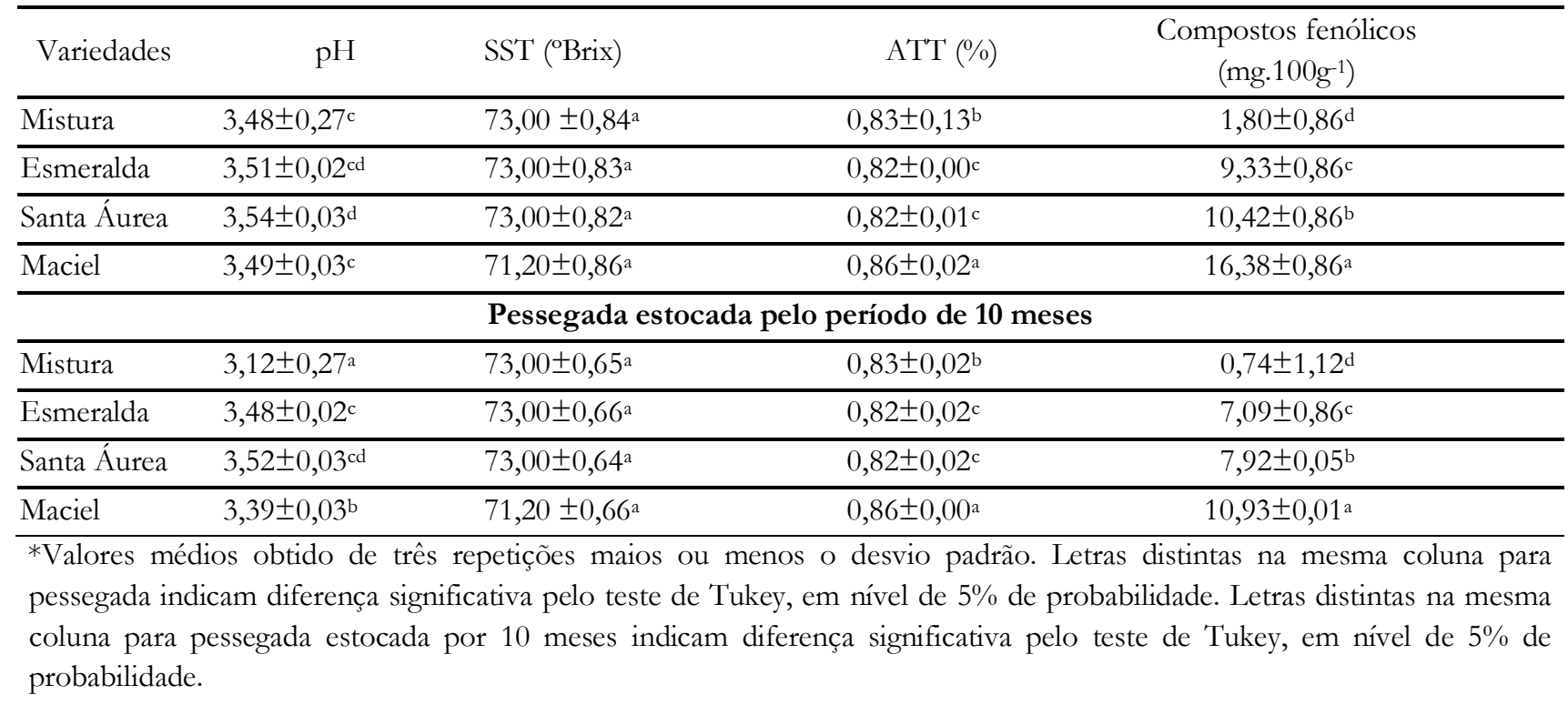

Fonte: Dados estatisticos obtidos. Crato-CE. Julho (2017). 
Observa-se pequeno acréscimo no valor do $\mathrm{pH}$ das pessegadas em relação ao valor de $\mathrm{pH}$ nas respectivas polpas, para todas as cultivares de pêssegos. Estes valores estão condizentes com a redução do conteúdo de acidez total, ocasionado, pelo menos em parte, pelo processo de evaporação de ácidos orgânicos durante o processamento da pessegada. Tendência oposta, de pequena redução no valor do $\mathrm{pH}$, ocorreu durante o período de estocagem da pessegada, para todas as formulações; no entanto, não observou-se acréscimo no conteúdo de acidez total nos doces. As concentrações de sólidos solúveis, expressos em ${ }^{\circ}$ Brix, das formulações de pessegadas atendem aos padrões estabelecidos pela legislação brasileira, que exige teores de sólidos solúveis mínimo de 65\% $(\mathrm{p} / \mathrm{p})$, e mesmo com período de estocagem os produtos não apresentaram alterações, mantendo-se na faixa de $73^{\circ}$ Brix. Foi observado que ocorreu sinerese em todas as amostras, e de forma muito reduzida.

De acordo com dados da EMBRAPA[22], um excesso de açúcar invertido ou de acidez fora do padrão ideal de 0,3 a $0,8 \%$, são considerados fatores que podem prejudicar a ação da pectina no preparo dos doces com possível formação de sinérese, mas este requisito não está de acordo com os resultados obtidos, outro fator que está relacionado à ocorrência de sinerese é a cocção excessiva do produto, o que pode ocorrer no processamento de pessegada. No presente estudo, o período de cocção dos doces foi de 15 minutos, mesmo período utilizado por Jacques ${ }^{[23]}$, os quais relatam como tempo adequado no processamento de doce em massa. Além disto, Martins ${ }^{[24]}$ afirma que a redução da acidez no produto pode contribuir para a redução da sinerese, neste caso a acidez manteve-se constante desde a obtenção do produto até final do período de armazenamento, podendo ser considerado um fator importante na formação da sinérese.

Com relação aos teores do total de compostos fenólicos pode-se observar que o processo de cocção não causou uma perda muito expressiva nos teores destes compostos após o processamento, exceto para o doce elaborado com a polpa da mistura de cultivares de pêssegos. O mesmo foi verificado por Jacques ${ }^{[23]}$, no processamento de doce em massa de amora preta, os quais verificaram que o conteúdo de compostos fenólicos praticamente permaneceu o mesmo antes e após o processamento. A cultivar de pêssego Maciel apresentou o maior conteúdo em compostos fenólicos, seguido do conteúdo nas cultivares Santa Áurea, da mistura e da cultivar Esmeralda. No entanto, o processo de elaboração e de estocagem da polpa pelo período de 10 meses, não afetou significativamente o conteúdo de compostos fenólicos nas diferentes cultivares de pêssego, apenas na amostra mistura. A perda acentuada de compostos fenólicos na pessegada formulada com a mistura de cultivares, em relação ao conteúdo na polpa, pode ter sido influenciada devido ao uso de diversas cultivares com diferentes graus de maturação dos frutos, enquanto que, nas demais formulações por cultivares, realizou-se controle do grau homogêneo de maturação dos frutos.

Santos ${ }^{[25]}$ salienta que o tratamento térmico (temperatura de aproximadamente $80^{\circ} \mathrm{C}$ ) pode inclusive provocar aumento da quantidade de compostos fenólicos no meio, devido o aumento da extração destes compostos das paredes celulares dos frutos. No entanto, durante o período de estocagem foi observado um decréscimo significativo no conteúdo de compostos fenólicos, para todas as formulações. Os decréscimos variaram de 57\% para a pessegada formulada com a mistura de cultivares a $24 \%$ para as pessegadas formuladas com as cultivares Esmeralda e Santa Áurea. Assim como ocorreu no processamento, a pessegada formulada com a mistura de cultivares de pêssegos apresentou as maiores perdas de compostos fenólicos durante o período de estocagem. O ácido hidróxibenzoico e o ácido gálico foram os únicos compostos fenólicos identificados por cromatografia líquida de alta eficiência na pessegada logo após processada e após 
10 meses de estocagem à temperatura ambiente (Tabela 3).

Tabela 3: Conteúdo de compostos fenólicos individuais (mg.100 g-1) em pessegadas elaboradas com cultivares selecionada e com a mistura de cultivares de pêssegos.

\begin{tabular}{lccc}
\hline & \multicolumn{2}{c}{ Pessegada } & \\
\cline { 2 - 3 } Cultivares & Ácido gálico & Ácido Hidroxibenzóico & Total \\
\hline Mistura & $0,58 \pm 0,12^{\mathrm{e}}$ & $\mathrm{Tr}$ & 0,58 \\
Esmeralda & $5,32 \pm 0,14^{\mathrm{b}}$ & $\mathrm{Tr}$ & 5,32 \\
Santa Áurea & $5,67 \pm 0,21^{\mathrm{b}}$ & $2,56 \pm 0,08^{\mathrm{a}}$ & 8,23 \\
Maciel & $8,32 \pm 0,09^{\mathrm{a}}$ & $1,22 \pm 0,32^{\mathrm{c}}$ & 9,54 \\
\hline & Pessegada armazenada pelo período de $\mathbf{1 0}$ meses & 0,62 \\
Mistura & $0,62 \pm 0,00^{\mathrm{e}}$ & $\mathrm{Tr}$ & 0,40 \\
Esmeralda & $0,40 \pm 0,07^{\mathrm{f}}$ & $\mathrm{Tr}$ & 5,02 \\
Santa Áurea & $3,67 \pm 0,20^{\mathrm{c}}$ & $1,35 \pm 0,27 \mathrm{~b}$ & 3,72 \\
Maciel & $2,37 \pm 0,21^{\mathrm{d}}$ & $1,35 \pm 0,07^{\mathrm{b}}$ & \\
\hline
\end{tabular}

*Médias de três repetições mais ou menos o desvio padrão. Letras distintas na mesma coluna indicam diferença significativa pelo teste de Tukey, em nível de 5\% de probabilidade. Tr-Traços. Nd- não detectado.

Fonte: Dados estatísticos obtidos. Crato-CE. Julho (2017).

$\mathrm{Na}$ tabela 3 verificou-se que o conteúdo de ácido gálico apresentou um acréscimo nas pessegadas ela boradas com as cultivares selecionadas, enquanto ocorreu drástica redução no conteúdo da pessegada elaborada com a mistura de cultivares, quando comparado com o conteúdo na respectiva polpa. Comportamento diferenciado em relação ao conteúdo de ácido gálico foi observado durante o armazenamento das pessegadas. $\mathrm{Na}$ pessegada elaborada com a mistura de cultivares $\mathrm{O}$ conteúdo praticamente não se alterou, mas foi observado um grande decréscimo no conteúdo das pessegadas elaboradas com cultivares selecionadas, onde as maiores perdas foram observadas na pessegada elaborada com a cultivar Esmeralda $(92 \%)$, e as menores na pessegada elaborada com a cultivar Santa Áurea (39\%), indicando grande instabilidade da cultivar esmeralda após período de armazenamento.

Comparando com o conteúdo total de compostos fenólicos, observou-se pequena perda devido ao processamento, onde o aumento no conteúdo de ácido gálico compensou as perdas dos outros compostos fenólicos, exceto para a pessegada elaborada com a mistura de cultivares. Os compostos catequina, epicatequina e quercitina, todos avaliados na polpa de pêssegos de cultivares selecionadas não foram identificadas nas respectivas pessegadas. Da mesma forma, o ácido hidroxibenzóico não foi identificado nas pessegadas elaboradas com a mistura de cultivares e da cultivar Esmeralda. Aparentemente, o tratamento térmico utilizado na elaboração do doce em massa exerceu grande efeito degradativo sobre estes compostos. No entanto, durante o período de estocagem foi observado perdas significativas tanto no conteúdo total de compostos fenólicos como no conteúdo dos compostos individuais, em todas as pessegadas.

A Figura 1 demonstra os produtos elaborados com a formulação da mistura de cultivares e as amostras de pessegada elaboradas com pêssegos de cultivares selecionadas. 


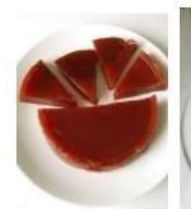

(A)

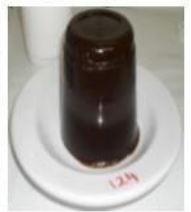

(B)

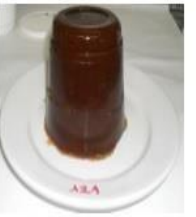

(C)

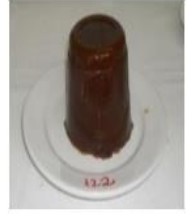

(D)
Figura 1: Amostras de pessegadas: Mistura de cultivares (A); Pessegadas usando cultivares selecionadas: Maciel (B) Esmeralda (C) e Santa Áurea (D).

Fonte: Dados obtidos. Crato-CE.

A pessegada resultante do processamento da cultivar Maciel apresentou alteração da visual da coloração característica, isto pode ter ocorrido devido as características intrínsecas desta cultivar apresentando maior sensibilidade aos efeitos do processo térmico.

\section{CONCLUSÃO}

A importância deste trabalho reside no fato de que a escolha de cultivares desde o cultivo até o processamento e estocagem das pessegadas, possibilita manter maior conteúdo de compostos bioativos no doce.

Das cultivares estudadas, o destaque foi cultivar Esmeralda, apresentando excelente qualidade como fruta in natura e para o processamento da pessegada.

Ocorreu uma redução no conteúdo de compostos fenólicos, durante o processo de elaboração da pessegada. Observou-se um decréscimo gradativo no conteúdo de todos os compostos bioativos avaliados durante o período de estocagem; mas ao final deste período ainda foi observado a presença destes compostos.

Os ácidos gálico e hidroxibenzóico foram os compostos fenólicos majoritários em todas as amostras, tanto na polpa quanto os doces, logo após o processamento e após o período de estocagem. Com isso o conteúdo de compostos fenólicos foi pouco afetado no processo de elaboração dos doces, exceto para a formulação com a mistura de cultivares de pêssego.

\section{REFERÊNCIAS}

[1] Durst RW, Weaver GW. Nutritional content of fresh and canned peaches. Journal of the Science of Food and Agriculture. 2013; 9(3): 593-603.

[2] Rickman JC, Barrett DM, Bruhn CM. Nutritional comparison of fresh, frozen and canned fruits and vegetables. Part 1. Vitamins $C$ and $B$ and phenolic compounds. Journalof the Science of Food and Agriculture. 2017; 87(6): 930-944.

[3] Segantini DM, Leonel S, Lima GPP, Costa SM, Ramos ARP. Caracterização da polpa de pêssegos produzidos em São Manuel - SP. Ciência Rural, Santa Maria. 2012; 42 (1): 51-57.

[4] Vizzotto M, Pereira ES, Schiavon MV, Franzon RBS. Compostos bioativos e ação antioxidante de genótipos contrastantes de pêssegos [Prunus persica (L.) Batsch]. Boletim de Pesquisa e Desenvolvimento. 2017; 26(2): 1678-2518.

[5] Krolow ACR. Preparo artesanal de doces em massa: Embrapa Clima Temperado. Documentos. 2009; 28(4);1.

[6] Machado, MIR. Compostos bioativos em pêssego (Prunus persica L.), pessegada e em pêssego em calda. Pelotas-RS. Universidade Federal de Pelotas, 2014.Tese de Doutorado.

[7] Cândido TLN, Freitas JB, Silva MR. Efeito da adição de xarope de glicose nas propriedades físico-químicas e aceitabilidade do doce de gabiroba. Nutrire: Revista Sociedade Brasileira Alimentos Nutrição. 2009; 34: 2: 1 10.

[8] Araújo PF, Rodrigues RS, Duarte AP. Qualidade de polpa de pêssegos preservada ou métodos combinados. Revista Brasileira de Tecnologia Agroindustrial. 2010; 1: 02: 8-16.

[9] BRASIL, Instrução normativa no1, de 7 de janeiro de 2000. Estabelece o Regulamento Técnico Geral para fixação dos Padrões de Identidade e Qualidade para polpa de fruta. Diário oficial da República Federativa do Brasil, 2000. 
[10] Gava AJ. Tecnologia de Alimentos Princípios e Aplicações, 8. ed. São Paulo: Nobel. 2008.

[11] INSTITUTO ADOLFO LUTZ-IAL. Normas Analíticas do Instituto Adolfo Lutz. Métodos químicos e físicos para análise de alimentos, Instituto Adolfo Lutz. São Paulo: 1985; 1, (3): 533.

[12] Lopes RLTL. Fabricação de geléias. Fundação Centro Tecnológico de Minas Gerais CETEC, 2007. Serviço Brasileiro de Respostas Técnicas. http://www.respostatecnica.org.br.

[13] Singleton VL, Rossi JA. Colorimetry of total phenolics whitphosphomolybdic phosphotungstic acid reagents. Am. J. Enol. Vitic. 1996; 16: 144-158.

[14] Hakkinen SH, Karenlampi SO, Heinonen M. HPLC Method for Screening of Flavonoids and Phenolic Acids in Berries. Journal. Food Agriculture. 1998;77: 543-551.

[15] Zambiazi RC. The role of endogenous lipid components on vegetable oil stability. Food and Nutritional Scienses Interdepartamental Program. Universiy of Manitoba Winnipeg, Manitoba, Canada. 1997:304.

[16] STATISTICA-STATSOFT, Inc. STATISTICA (software de análise de dados do sistema), aversão 7 . www.statsoft.com. 2004.

[17] EMBRAPA, Clima Temperado, Sistemas de Produção, 4, ISSN 1806-9207 Versão Eletrônica, Cultivo do Pessegueiro, Nov./2005. Disponível em <http://www.http:// sistemasdeproducao.cnptia.embrap a.br>. Acesso em: 29 set. 2018 15:15.

[18] Costa AC. Estudo de conservação de pêssego [Prunus pérsica (L) Batsch] minimamente processado, Tese (Doutorado). Pelotas. Programa de Pós-Graduação em Ciência e Tecnologia Agroindustrial. Faculdade de Agronomia Eliseu. 2010.

[19] Fachinello JC, Nachtigal J C. Embrapa clima temperado, [Publicação on line]; 2014 [acesso EM: 22/04/2016] Disponível em: <www. embrapa clima temperado .com.br
[20] Chitarra MIF, Chitarra AB. Pós-colheita de frutos e hortaliças: fisiologia e manuseio. Lavras: ESAL, FAEPE. 2009.

[21] Silva JA. Tópicos da Tecnologia dos Alimentos. São Paulo: Varela. 2004.

[22] EMBRAPA, Iniciando um pequeno grande negócio agroindustrial: Frutas em calda, geléias e doces. Brasília. Embrapa, Sebrae (Série Agronegócios) Parte 1: Processo de produção, 2003: 10-84.

[23] Jacques AC, Pertuzatti PB, Barcia MT, Zambiazi RC. Doce em Massa de Amora Preta (Rubus spp.): Análise Sensorial e de Fitoquímicos; Alimentos Nutrição, Araraquara. 2009; 20 (4): 625-631.

[24] Martins MLA, Borges SV, Deliza R, Castro FT, Cavalcante NB. Características de doce em massa de umbu verde e maduro e aceitação pelos consumidores. Pesquisa Agropecuária Brasileira. ISSN 0100-204X. 2007; 1; 4 (9): 1329-1333.

[25] Santos MS, Lima DEJJ, Petkowicz CLO, Candido LMB. Chemical characterization an devaluation of th antioxidant potential of gabiroba jam (Campomanesia xanthocarpa Berg). Acta Sciencia Agronomica, Maringá. 2013; 35; 1 . 